\title{
Pengaruh Penerapan Alat Peraga Melalui Model Pembelajaran Numbered Head Together (NHT) Terhadap Hasil Belajar Siswa Pada Materi Bangun Ruang Sisi Lengkung di Kelas IX SMP Negeri 5 Padangsidimpuan
}

\author{
Oleh: \\ Intan Parwati Pane \\ Mariam Nasution, M.Pd
}

\begin{abstract}
The background of this research is the low mathematics learning outcomes of class IX students of SMP Negeri 5 Padangsidimpuan because the teacher's learning process is not able to create students 'attention, students' enthusiasm in attending classes is still low, so students have difficulty in answering mathematical problems / problems especially in wakefulness curved side space that causes student learning outcomes not to the maximum. This study aims to determine the effect of the application of teaching aids through the numbered heads together (NHT) learning model on student learning outcomes in the material to construct curved side spaces in class IX SMP Negeri 5 Padangsidimpuan.

This study refers to Jerome S. Bruner's learning theory which says that learning mathematics will be more successful if the teaching process is directed at the concepts and structures made in the subject being taught, in addition to the related relationships between concepts and structures .

This research is a quantitative research with an experimental method of classical experimental design. The population of this study was all students of class IX of SMP Negeri 5 Padangsidimpuan consisting of 12 classes as many as 297 students, and for the sample taken using cluster random sampling technique which is 48 students. The control class is 24 students and the experimental class is 24 students. The instrument used as a data collector is a test given twice, namely before the pretest and posttest. While for data processing and data analysis is done using the t-test formula.

Based on the normality and homogeneity test both classes are normally distributed and homogeneous. The t-test is obtained from the results of hypothesis testing which shows tcount> $\mathrm{t}$ table, namely 10.007> 2.0129. So it can be concluded that $\mathrm{Ho}$ is rejected and $\mathrm{H} 1$ is accepted, meaning that there is a significant influence between the application of props through the numbered heads together learning model on student learning outcomes in the material to construct curved side spaces in class IX SMP Negeri 5 Padangsidimpuan.
\end{abstract}




\begin{abstract}
Abstrak
Latar belakang penelitian ini adalah rendahnya hasil belajar matematika siswa kelas IX SMP Negeri 5 Padangsidimpuan disebabkan karena dalam proses pembelajaran guru tidak mampu menciptakan perhatian siswa, antusias siswa dalam mengikuti pelajaran masih rendah, sehingga siswa mengalami kesulitan dalam menjawab persoalan/permasalahan matematika terutama pada materi bangun ruang sisi lengkung yang menyebabkan hasil belajar siswa tidak maksimal. Penelitian ini bertujuan untuk mengetahui pengaruh penerapan alat peraga melalui model pembelajaran numbered heads together (NHT) terhadap hasil belajar siswa pada materi bangun ruang sisi lengkung di kelas IX SMP Negeri 5 Padangsidimpuan.

Penelitian ini mengacu kepada teori belajar Jerome S. Bruner yang mengatakan bahwa belajar matematika akan lebih berhasil jika proses pengajaran diarahkan kepada konsep-konsep dan struktur-struktur yang terbuat dalam pokok bahasan yang diajarkan, disamping hubungan yang terkait antara konsep-konsep dan struktur-struktur.

Penelitian ini merupakan penelitian kuantitatif dengan metode eksperimen jenis desain eksperimen klasik (classical experimental design). Populasi penelitian ini adalah keseluruhan siswa kelas IX SMP Negeri 5 Padangsidimpuan yang terdiri dari 12 kelas sebanyak 297 siswa, dan untuk sampelnya diambil menggunakan teknik cluster random sampling yaitu sebanyk 48 siswa. Kelas kontrol sebanyak 24 siswa dan kelas eksperimen 24 siswa. Instrumen yang digunakan sebagai pengumpul data adalah tes yang diberikan sebanyak dua kali, yaitu sebelum pretest dan postest. Sedangkan untuk pengolahan data dan analisis data dilakukan dengan menggunakan rumus uji-t.

Berdasarkan uji normalitas dan homogenitas kedua kelas berdistribusi normal dan homogen. Pengujian uji-t diperoleh hasil uji hipotesis yang menunjukkan $t_{\text {hitung }}>\mathrm{t}_{\text {tabel }}$ yaitu 10,007 $>2,0129$. Maka dapat diambil kesimpulan Ho ditolak dan $\mathrm{H}_{1}$ diterima, berarti ada pengaruh yang signifikan antara penerapan alat peraga melalui model pembelajaran numbered heads together terhadap hasil belajar siswa pada materi bangun ruang sisi lengkung di kelas IX SMP Negeri 5 Padangsidimpuan.
\end{abstract}

Kata Kunci : Alat Peraga, Model Pembelajaran Numbered Heads Together, Hasil Belajar, Materi Bangun Ruang Sisi Lengkung, Matematika. 


\section{A. Pendahuluan}

Pendidikan adalah usaha menolong orang agar ia mampu menyelesaikan masalah yang dihadapinya. ${ }^{1}$ Pendidikan merupakan suatu kebutuhan sepanjang hayat, dan setiap manusia membutuhkan pendidikan baik pendidikan di dalam keluarga, sekolah maupun masyarakat. Selain itu, pendidikan merupakan kegiatan yang dilakukan secara sengaja dan sistematis dengan tujuan menggali dan mengembangkan potensi-potensi dalam diri manusia, melalui pendidikan diharapkan terjadi peningkatan sumber daya manusia.

Di Indonesia, sistem pendidikan terus menerus mengalami perubahan baik perubahan kurikulum maupun proses belajar mengajar seperti yang berlangsung sekarang ini. Oleh karena itu guru sebagai tenaga pendidik mempunyai tujuan utama dalam kegiatan belajar mengajar disekolah supaya dapat mewujudkan kegiatan belajar mengajar yang menyenangkan, sehingga dapat berdampak baik terhadap pencapaian hasil belajar (kognitif) yang merupakan konstribusi guru yang diupayakan sejak kegiatan belajar mengajar. Dari hasil belajar inilah dapat dilihat suatu keberhasilan siswa terhadap pemahaman tentang materi atau bahan ajar.

Matematika adalah salah satu cabang ilmu yang diajarkan di sekolah dan juga merupakan salah satu mata pelajaran yang memiliki peranan penting baik dalam pendidikan, lingkungan maupun dalam kehidupan sosial lainnya. Prestasi matematika siswa di Indonesia sungguh sangat memprihatinkan. Salah satu penyebab rendahnya prestasi matematika siswa adalah masih banyak siswa yang tidak suka matematika, bahkan mendengar kata 'matematika' saja rasanya ia tidak senang. Nah, dengan keadaan begitu bagaimana bisa seorang siswa mengembangkan potensinya? Sedangkan mempelajari matematika itu saja mereka setengah hati. Dengan permasalahan seperti itu, tugas seorang guru matematika bertambah, yaitu bagaimana seorang guru mengajarkan pelajaran yang dianggap seperti monster bagi siswa, agar pembelajaran bisa lebih menyenangkan dan bermakna, sehingga hasil belajar siswa pun meningkat. Apalagi dalam pembelajaran matematika yang kajiannya adalah bidang abstrak, karena keabstrakannya ini kebanyakan guru kesulitan dalam mengembangkan pembelajaran matematika.

Guru merupakan faktor penting dalam menentukan keberhasilan pembelajaran. Pemilihan model dan media pembelajaran merupakan bagian terpenting yang harus dipilih seorang guru. Penggunaan media pembelajaran harus disesuaikan dengan materi pembelajaran. Apabila guru salah dalam memilih media pembelajaran maka akan berakibat pada hasil belajar siswa.

Menurut Gerlach dan Ely yang dikutip oleh Azhar Arsyad bahwa media apabila dipahami secara garis besar adalah manusia, materi atau kejadian yang membangun kondisi yang membuat siswa mampu memperoleh pengetahuan, keterampilan, atau sikap. ${ }^{2}$

1 Ahmad Tafsir, Filsafat Pendidikan Islami (Bandung: Remaja Rosdakarya, 2008), hlm. 39.

${ }^{2}$ Azhar Arsyad, Media Pembelajaran (Jakarta : Raja Grafindo Persada, 2013), hlm.3 
Berdasarkan hasil wawancara dengan ibu Masri Pakpahan, S.Pd selaku guru matematika di SMP N 5 Padangsidimpuan, mengatakan bahwa pembelajaran matematika yang biasa digunakan masih dengan pembelajaran konvensional yang pembelajarannya berpusat pada guru. Hal ini mengakibatkan kurang berkembangnya kemampuan siswa, serta jarang didapatkan respon siswa terhadap pokok bahasan yang diajarkan. Terutama pada materi bangun ruang sisi lengkung mengenai unsur-unsur, luas permukaan dan volume bangun ruang sisi lengkung. Tidak jarang siswa kesulitan menjawab soal-soal yang berbeda dengan contoh yang diberikan guru karena pemahaman siswa terhadap pokok bahasan tersebut kurang memadai. Dalam menjelaskan materi bangun ruang sisi lengkung guru tidak menyediakan media yang mendukung pelajaran, sehingga siswa hanya memahami materi bangun ruang sisi lengkung secara abstrak. Dalam proses pembelajaran banyak siswa yang tidak memiliki semangat belajar matematika karena guru hanya meggunakan media buku paket dan papan tulis. Hal ini membuat siswa merasa bosan, malas dan kesulitan dalam memahami pelajaran matematika serta anggapan siswa bahwa pelajaran matematika kurang bermanfaat dalam kehidupan sehari-hari. Tentunya hal ini mengakibatkan siswa tidak dapat mencapai hasil yang optimal. Hal ini dibuktikan dengan rendahnya nilai ulangan harian pada materi bangun ruang sisi lengkung dan berakibat pada hasil belajar matematika siswa yang hanya mencapai ketuntasan 38,5\% dan tidak mencapai ketuntasan sebesar 61,5\%. ${ }^{3}$

Dalam hal ini, peneliti melakukan uji coba penerapan alat peraga melalui model pembelajaran Numbered Heads Together (NHT). Karena berdasarkan teori pengguanaan media dalam proses belajar adalah Dale's Cone of Experience (Kerucut Pengalaman Dale), yang dicetuskan oleh Edgar Dale. Pengalaman langsung akan memberikan kesan paling utuh dan paling bermakna mengenai informasi dan gagasan yang terkandung dalam pengalaman itu. Dikarenakan melibatkan indera penglihatan, pendengaran, perasaan, penciuman dan peraba. Teori ini di dukung dengan teori Bruner yang mengatakan bahwa anak akan belajar dengan baik jika melalui tiga tahap yaitu tahap afektif (pengalaman langsung dengan benda-benda nyata), tahap ikonik (dengan gambar, lukisan dan foto) dan tahap simbolik (pengalaman abstrak).

Alat peraga merupakan salah satu media yang dapat digunakan untuk memusatkan perhatian peserta didik agar terfokus dalam pembelajaran. Alat peraga bisa dikatakan sebagai alat yang bisa merangsang siswa untuk terjadinya proses belajar. Media pembelajaran meliputi perangkat keras yang dapat mengantarkan pesan dan perangkat lunak yang mengandung pesan. Media tidak hanya berupa alat atau bahan, tetapi juga hal lain yang memungkinkan siswa memperoleh pengetahuan. ${ }^{4}$ Media pembelajaran sangat

3 Masri Pakpahan, Guru SMP Negeri 5 Padangsidimpuan, wawancara pada tanggal 18 Oktober 2016.

4 Wina Sanjaya, Perencanaan dan Desain Sistem Pembelajaran (Jakarta: Kencana Prenada Media Group, 2008), hlm. 244 
menunjang tingkat pemahaman peserta didik dapat memperoleh pengalaman belajar secara langsung. ${ }^{5}$ Untuk meningkatkan hasil belajar, siswa harus memperhatikan dan berpartisipasi dalam proses pembelajaran. Banyak alat peraga yang dipakai untuk meningkatkan hasil belajar siswa pada materi bangun ruang sisi lengkung, namun peneliti tertarik untuk menerapkan alat peraga 3R (reduce, reuse dan recycle). Alat peraga 3R untuk materi bangun ruang sisi lengkung dalam penelitian ini adalah alat peraga yang terdiri dari benda-benda di lingkungan sekitar yang sudah tidak terpakai yang berbentuk tabung, kerucut dan bola seperti kaleng susu, kaleng biskuit, botol minuman bekas, dan topi ulang tahun bekas pakai, serta bola plastik mainan. Kertas koran, kertas bekas kalender, karton bekas dus susu digunakan untuk membuat jaring-jaring tabung dan kerucut. Karena alat peraga ini mudah untuk digunakan oleh siswa. Alat peraga ini juga dapat dengan mudah diaplikasikan dalam pembelajaran materi bangun ruang sisi lengkung.

Tidak hanya alat peraga saja yang dapat meningkatkan hasil belajar siswa, tetapi penerapan model pembelajaran yang bervariasi dapat meningkatkan partisipasi siswa dalam mengikuti pembelajaran. Berdasarkan pertimbangan peneliti, peneliti merasa model pembelajaran yang sesuai dengan masalah di atas adalah model pembelajaran Numbered Head Together (NHT). Salah satu kelebihan model pembelajaran Numbered Head Together (NHT) bisa meningkatkan keaktifan dan kerjasama antar siswa, sebab dalam pembelajaran siswa ditempatkan dalam suatu kelompok untuk berdiskusi sehingga proses belajar akan lebih terfokus secara mandiri di setiap kelompok. Dan model pembelajaran Numbered Head Together (NHT) belum pernah diterapkan di SMP negeri 5 Padangsidimpuan.

Dari uraian permasalahan di atas, peneliti menduga bahwa penggunaan alat peraga dan model pembelajaran inilah yang menjadi faktor utama dalam penentuan tinggi rendahnya hasil belajar siswa pada umumnya. Guru harus mampu mengelola kelas dan mampu membangkitkan imajinasi siswa agar berpartisipasi dalam kegiatan belajar mengajar. Maka diperlukan perpaduan penerapan alat peraga melalui model pembelajaran Numbered Heads Together (NHT) dengan tujuan dapat meningkatkan hasil belajar sesuai dengan harapan dan dapat mengaktifkan siswa dan memberi suatu masukan baru kepada siswa. Hal inilah yang mendorong peneliti untuk meneliti Pengaruh Penerapan Alat Peraga Melalui Model Pembelajaran NHT Terhadap Hasil Belajar Siswa Pada Materi Bangun Ruang Sisi Lengkung Di Kelas IX SMP Negeri 5 Padangsidimpuan.

\section{B. METODOLOGI PENELITIAN}

\section{Lokasi dan Waktu Penelitian}

Tempat penelitian dilakukan di SMP Negeri 5 Padangsidimpuan pada kelas IX Tahun ajaran 2016/2017 yang beralamat di Jl. Perintis Kemerdekaan Padangsidimpuan.

${ }^{5}$ Basyiruddin Usman dan Asnawir, Media Pembelajaran (Jakarta: Ciputat Pers, 2002), hlm.19 


\section{Jenis Penelitian}

Jenis penelitian ini adalah penelitian kuantitatif dengan metode penelitian eksperimen. Dengan menggunakan desain non randomized control group pre test post test design.

\section{Populasi dan Sampel}

Dari pendapat di atas, maka penulis mengambil kesimpulan bahwa populasi adalah keseluruhan dari subjek penelitian yang akan menjadi sumber data penelitian. Yang menjadi populasi dalam penelitian ini adalah seluruh siswa kelas IX SMP Negeri 5 Padangsidimpuan yang berjumlah 297 orang siswa yang terdiri dari 12 kelas.

Sampel penelitian ini mengambil dua kelompok yaitu kelas $\mathrm{IX}^{10}$ berjumlah 24 siswa sebagai kelas eksperimen dan kelas IX ${ }^{11}$ berjumlah 24 siswa sebagai kelas kontrol.

\section{Instrumen Pengumpulan Data}

Untuk memperoleh data yang diperlukan dalam rangka analisis terhadap kedua instrumen, maka instrument pemngumpulan data yang digunakan adalah tes. Adapun tes yang digunakan untuk kedua variabel dalam penelitian ini adalah tes objektif yaitu bentuk pilihan ganda (multiple choice) sebanyak 20 soal dengan empat alternatif jawaban (a, b, c, dan d). Soal bentuk pilihan ganda diskor dengan memberi angka 1 (satu) bagi setiap butir jawaban yang benar dan angka 0 bagi butir jawaban yang salah. ${ }^{6}$

\section{Teknik Analisis Data}

1. Analisis Data Awal (Pre-test) dan Data Hasil (Post-test)

\section{a. Uji Normalitas}

Uji normalitas penelitian ini menggunakan SPSS 17 : uji kolmogorov-Smirnov. ${ }^{7}$

\section{b. Uji Homogenitas Varians}

Uji homogenitas varians digunakan untuk mengetahui apakah kelas eksperimen dan kelas kontrol mempunyai varians yang sama atau tidak. Jika kedua kelompok mempunyai varians yang sama maka kedua kelompok homogen. Untuk menguji kesamaan varians tersebut, maka rumus yang digunakan adalah:

$$
F_{\text {hitung }}=\frac{s_{1}^{2}}{s_{2}^{2}}
$$

${ }^{6}$ Nana Sudjana, Penilaian Hasil Proses Belajar Mengajar (Bandung: PT. Remaja Rosdakarya, 1999), hlm.54

7 Agus Irianto, Statistik: Konsep Dasar, Aplikasi dan Pengembangannya (Jakarta: Kencana, 2004), hlm.272 
Keterangan:

$s_{1}^{2}:$ varians terbesar

$s_{2}^{2}:$ varians terkecil

Kriteria pengujian adalah $\mathrm{H}_{\mathrm{o}}$ diterima jika $\mathrm{F}_{\text {hitung }} \geq \mathrm{F}_{\text {tabel }}$ berarti tidak homogen, dan jika $F_{\text {hitung }} \leq \mathrm{F}_{\text {tabel }}$ berarti homogen. Dengan taraf nyata $5 \%$ dan dk pembilang $=\left(n_{1}-1\right)$, dk penyebut $=\left(n_{2}-1\right)$.

\section{c. Uji Kesamaan Dua Rata-rata}

Menurut Sugiyono bahwa terdapat beberapa rumus $t$ test yang digunakan untuk pengujian, dan berikut ini diberikan pedoman penggunaannya: ${ }^{8}$

(1) Bila jumlah anggota sampel sama $\left(\mathrm{n}_{1}=\mathrm{n}_{2}\right)$ dan varians homogen $\left(\sigma_{1}^{2}=\sigma_{2}^{2}\right)$, maka dapat digunakan $t$-test baik untuk separated maupun pool varian. Untuk melihat harga t tabel, digunakan $\mathrm{dk}$ $=\mathrm{n}_{1}+\mathrm{n}_{2}-2$.

(2) Bila $\mathrm{n}_{1} \neq \mathrm{n}_{2}$ dan varians homogen $\left(\sigma_{1}^{2}=\sigma_{2}^{2}\right)$, dapat digunakan $t$ test dengan pooled varian. Derajat kebebasannya $(\mathrm{dk})=n_{1}+$ $n_{2}-2$

(3) Bila $n_{1}=n_{2}$, varians tidak homogen $\left(\sigma_{1}^{2} \neq \sigma_{2}^{2}\right)$ dapat digunakan rumus separated varians dan polled varian dengan $\mathrm{dk}=n_{1}-1$ atau $n_{2}-1$.

(4) Bila $n_{1} \neq n_{2}$ dan varians tidak homogen $\left(\sigma_{1}^{2} \neq \sigma_{2}^{2}\right)$. Untuk ini digunakan $t$-test dengan separated varian. Harga $\mathrm{t}$ sebagai pengganti t tabel dihitung dari selisih harga $\mathrm{t}$-tabel dengan $\mathrm{dk}=$ $\left(n_{1}-1\right)$ dan $\mathrm{dk}=\left(n_{2}-1\right)$ kemudian dibagi 2 , dan ditambahkan dengan harga t yang terkecil.

Rumus Polled varian adalah:

$$
t=\frac{\bar{X}_{1}-\bar{X}_{2}}{\sqrt{\frac{\left(n_{1}-1\right) s_{1}^{2}+\left(n_{2}-1\right) s_{2}^{2}}{n_{1}+n_{2}-2}\left(\frac{1}{n_{1}}+\frac{1}{n_{2}}\right)}}
$$

Keterangan:

$\bar{X}_{1}=$ mean sampel kelompok kontrol

$\bar{X}_{2}=$ mean sampel kelompok eksperimen

$s_{1}^{2}=$ varians kelompok kontrol

$s_{2}^{2}=$ varians kelompok eksperimen

$n_{1}=$ banyaknya sampel kelompok eksperimen

$n_{2}=$ banyaknya sampel kelompok kontrol

\section{d. Uji Perbedaan Rata-rata}

Jika $n$ yang sama $(\mathrm{n} 1=\mathrm{n} 2)$ dan varian homogen, maka pengujian $t$-test menggunakan runus Polled Varians. Jika data kedua

${ }^{8}$ Sugiyono, Op. Cit., hlm. 196. 
kelas berdistribusi normal dan kedua variansinya homogen, rumus uji t' yang digunakan ialah: ${ }^{9}$

Keterangan:

$$
t=\frac{\bar{X}_{1}-\bar{X}_{2}}{\sqrt{\frac{\left(n_{1}-1\right) s_{1}^{2}+\left(n_{2}-1\right) s_{2}^{2}}{n_{1}+n_{2}-2}\left(\frac{1}{n_{1}}+\frac{1}{n_{2}}\right)}}
$$

$\bar{X}_{1}=$ mean sampel kelompok kontrol

$\bar{X}_{2}=$ mean sampel kelompok eksperimen

$s_{1}^{2}=$ varians kelompok kontrol

$s_{2}^{2}=$ varians kelompok eksperimen

$n_{1}=$ banyaknya sampel kelompok eksperimen

$n_{2}=$ banyaknya sampel kelompok kontrol

Kriteria pengujian Ho diterima apabila $t_{\text {hitung }}<\mathrm{t}_{\text {tabel. }}$. Dengan $\mathrm{dk}=\left(\mathrm{n}_{1}\right.$ $+\mathrm{n}_{2}-2$ ) dan tolak Ho jika t mempunyai harga-harga lain. ${ }^{10}$

\section{Hasil Penelitian}

a. Analisis Data Pretest

\section{Uji Normalitas Data Pretest}

Tabel 1. Hasil Uji Normalitas Data Pretest Kelas Kontrol dengan SPSS 17

\section{Tests of Normality}

\begin{tabular}{|r|r|r|r|r|r|r|}
\hline & \multicolumn{3}{|c|}{ Kolmogorov-Smirnov $^{\text {a }}$} & \multicolumn{3}{c|}{ Shapiro-Wilk } \\
\cline { 2 - 7 } & Statistic & \multicolumn{1}{|c|}{$\mathrm{df}$} & \multicolumn{1}{c|}{ Sig. } & Statistic & \multicolumn{1}{c|}{ df } & \multicolumn{1}{c|}{ Sig. } \\
\hline hasil belajar & .174 & 24 & .057 & .884 & 24 & .010 \\
\hline
\end{tabular}

a. Lilliefors Significance Correction

$$
\text { Zhitung }
$$

Berdasarkan tabel di atas nilai signifikansi 0,057 > 0,05 maka data pre test hasil belajar kelompok kontrol berdistribusi normal.

\footnotetext{
${ }^{9}$ Ahmad Nizar, Loc. Cit.
}

10 Ahmad Nizar, Statistik Untuk Penelitian Pendidikan (Bandung: Cita Pustaka Media, 2014), hlm. 73. 
Tabel 2. Hasil Uji Normalitas Data Pre Test Hasil Belajar Kelas Eksperimen dengan SPSS 17

Tests of Normality

\begin{tabular}{|c|c|c|c|c|c|c|}
\hline & \multicolumn{3}{|c|}{ Kolmogorov-Smirnov ${ }^{\mathrm{a}}$} & \multicolumn{3}{|c|}{ Shapiro-Wilk } \\
\hline & Statistic & df & Sig. & Statistic & df & Sig. \\
\hline hasil belajar & .125 & 24 & $.200^{*}$ & .936 & 24 & .131 \\
\hline
\end{tabular}

*. This is a lower bound of the true significance.

Berdasarkan tabel di atas nilai signifikansi 0,200>0,05 maka data pretest hasil belajar kelompok eksperimen berdistribusi normal.

Jadi dapat disimpulkan bahwa data hasil belajar pre test seluruhnya berdistribusi normal. Sehingga analisis perbedaan (komparatif) data hasil belajar pretest menggunakan statistik parametris dengan $t$ test.

\section{Uji Homogenitas Data Pretest}

Untuk mengetahui apakah varian ke dua sampel homogen atau tidak, maka perlu dilakukan uji homogenitas variannya terlebih dahulu dengan uji F. Berdasarkan perhitungan yang diperoleh:

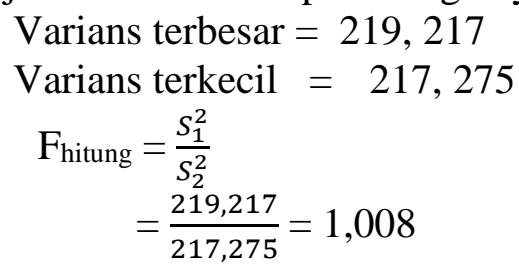

Harga $F_{\text {hitung }}$ selanjutnya dibandingkan dengan harga $F_{\text {tabel }}$ dengan $\mathrm{dk}$ pembilang $=\mathrm{n}-1=24-1=23$ (untuk varian terbesar) dan $\mathrm{dk}$ penyebut $=\mathrm{n}-1=24-1=23$ (untuk varian terkecil). Taraf signifikansi $=$ 0,05 , maka dicari pada Tabel $F$ didapat $F_{\text {tabel }}=2,014$. Dengan kriteria pengujian sebagai berikut: Jika $F$ hitung $<F$ tabel berarti homogen dan jika $\mathrm{F}$ hitung $>\mathrm{F}$ tabel berarti tidak homogen. Berdasarkan perhitungan $\mathrm{F}$ hitung $<\mathrm{F}$ tabel yaitu $1,008<2,014$ ini berarti varian ke dua data pre test hasil belajar homogen.

\section{Uji Kesamaan rata-rata (t- test) Data Hasil Belajar}

Karena $\mathrm{n}$ yang sama $\left(\mathrm{n}_{1}=\mathrm{n}_{2}\right)$ dan varian data homogen, maka pengujian t-test menggunakan rumus polled varian. Peneliti menggunakan aplikasi SPSS 17 untuk mempermudah perhitungan. 
Tabel 3. Hasil Uji T-test Pretest hasil belajar siswa

\begin{tabular}{|l|l|r|r|r|c|}
\hline \multicolumn{7}{|c|}{ Group Statistics } \\
\hline \multirow{2}{*}{} & Kelas & N & Mean & $\begin{array}{c}\text { Std. } \\
\text { Deviation }\end{array}$ & $\begin{array}{c}\text { Std. Error } \\
\text { Mean }\end{array}$ \\
\hline Nilai & kelas kontrol & 24 & 46.6667 & 14.74026 & 3.00884 \\
\cline { 2 - 6 } & $\begin{array}{l}\text { kelas } \\
\text { eksperimen }\end{array}$ & 24 & 50.0000 & 14.80599 & 3.02226 \\
\hline
\end{tabular}

\begin{tabular}{|c|c|c|c|c|}
\hline \multicolumn{5}{|c|}{ Independent Samples Test } \\
\hline & & & \multicolumn{2}{|c|}{ Pretest } \\
\hline & & & $\begin{array}{c}\text { Equal } \\
\text { variances } \\
\text { assumed }\end{array}$ & $\begin{array}{c}\text { Equal } \\
\text { variances } \\
\text { not assumed }\end{array}$ \\
\hline \multirow{2}{*}{$\begin{array}{l}\text { Levene's Test } \\
\text { for Equality } \\
\text { of Variances }\end{array}$} & & $\mathrm{F}$ & .224 & \\
\hline & & Sig. & .638 & \\
\hline \multirow{7}{*}{$\begin{array}{l}\text { t-test for } \\
\text { Equality of } \\
\text { Means }\end{array}$} & & $\mathrm{T}$ & .782 & .782 \\
\hline & & Df & C & 45.999 \\
\hline & & Sig. (2-tailed) & .438 & .438 \\
\hline & & Mean Difference & 3.33333 & 3.33333 \\
\hline & & $\begin{array}{l}\text { Std. Error } \\
\text { Difference }\end{array}$ & 4.26465 & 4.26465 \\
\hline & $95 \%$ & Lower & -11.91762 & -11.91762 \\
\hline & $\begin{array}{l}\text { Interval of } \\
\text { the } \\
\text { Difference }\end{array}$ & Upper & 5.25095 & 5.25096 \\
\hline
\end{tabular}

Berdasarkan hasil perhitungan SPSS di atas diperoleh nilai sign(2-tailed) sebesar 0,438>0,05, maka sesuai dengan dasar pengambilan keputusan dari Uji Independent Sample T-test, maka 
dapat disimpulkan bahwa $\mathrm{H}_{0}$ diterima dan $\mathrm{H}_{1}$ ditolak, yang artinya bahwa tidak ada perbedaan antara rata-rata hasil belajar kelas kontrol dan kelas eksperimen. Oleh karena itu, dapat diketahui bahwa antara kelompok kontrol dan kelompok eksperimen memiliki kemampuan awal yang yang sama, khususnya mencakup hasil belajarnya.

\section{b. Analisis Data Postest}

\section{Uji Normalitas Data Posttest}

Uji normalitas digunakan untuk mengetahui bahwa data yang diperoleh dari maisng-masing kelas eksperimen meupun kelas kontrol berdistribusi normal. Peneliti menggunakan aplikasi SPSS 17 untuk menguji normalitas data dengan uji Kormogorov-Smirnov.

Tabel 4. Hasil Uji Normalitas Data Hasil Belajar Siswa Kelas Kontrol dengan SPSS 17

\section{Tests of Normality}

\begin{tabular}{|l|r|r|r|r|r|r|}
\hline & \multicolumn{3}{|c|}{ Kolmogorov-Smirnov $^{\mathrm{a}}$} & \multicolumn{4}{c|}{ Shapiro-Wilk } \\
\cline { 2 - 7 } & Statistic & \multicolumn{1}{|c|}{ Df } & \multicolumn{1}{c|}{ Sig. } & Statistic & \multicolumn{1}{c|}{ df } & \multicolumn{1}{c|}{ Sig. } \\
\hline Nilai & .170 & 24 & .072 & .861 & 24 & .003 \\
\hline
\end{tabular}

Berdasarkan tabel di atas nilai signifikansi menunjukkan nilai 0,072 > 0,05 maka data hasil belajar posttest kelompok kontrol berdistribusi normal.

Tabel 5. Hasil Uji Normalitas Data Hasil Belajar Siswa Kelas Ekperimen dengan SPSS 17

Tests of Normality

\begin{tabular}{|l|r|r|r|r|r|r|}
\hline & \multicolumn{3}{|c|}{ Kolmogorov-Smirnov $^{\text {a }}$} & \multicolumn{3}{c|}{ Shapiro-Wilk } \\
\cline { 2 - 7 } & Statistic & \multicolumn{1}{|c|}{ df } & \multicolumn{1}{c|}{ Sig. } & Statistic & \multicolumn{1}{c|}{ df } & \multicolumn{1}{c|}{ Sig. } \\
\hline Nilai & .157 & 24 & .128 & .905 & 24 & .028 \\
\hline
\end{tabular}


Berdasarkan tabel di atas nilai signifikansi menunjukkan nilai 0,128> 0,05 maka data hasil belajar posttest kelompok kontrol berdistribusi normal.

Jadi dapat disimpulkan bahwa data posttest hasil belajar seluruhnya berdistribusi normal. Sehingga pengujian hipototesis komparatif hasil belajar posttest menggunakan statistik parametris.

\section{Uji Homogenitas Data Postest Hasil Belajar}

Untuk mengetahui apakah varian ke dua sampel homogen atau tidak, maka perlu diuji homogenitas variannya terlebih dahulu dengan uji F.

$$
\begin{aligned}
F_{\text {hitung }} & =\frac{S_{1}^{2}}{S_{2}^{2}} \\
& =\frac{112,196}{75,984}=1,48
\end{aligned}
$$

Harga $F_{\text {hitung }}$ selanjutnya dibandingkan dengan harga $F_{\text {tabel }}$ dengan $\mathrm{dk}$ pembilang $=\mathrm{n}-1=24-1=23$ (untuk varian terbesar) dan $\mathrm{dk}$ penyebut $=\mathrm{n}-1=24-1=23$ (untuk varian terkecil). Taraf signifikansi $=$ 0,05 , maka dicari pada Tabel $\mathrm{F}$ didapat $\mathrm{F}_{\text {tabel }}=2.014$. Dengan kriteria pengujian sebagai berikut: Jika $F_{\text {hitung }}>F_{\text {tabel }}$ berarti tidak homogen, dan jika $F_{\text {hitung }}<\mathrm{F}_{\text {tabel }}$ berarti homogen. Berdasarkan perhitungan $\mathrm{F}_{\text {hitung }}<$ $F_{\text {tabel }}$ yaitu $1,48<2,014$ berarti varian kedua data postest hasil belajar homogen.

\section{Pengujian Hipotesis Penelitian} kriteria

Uji hipotesis menggunakan uji perbedaan dua rata-rata dengan

$$
\begin{aligned}
& H_{0}: \mu_{1} \leq \mu_{2} \\
& H_{1}: \mu_{1} \geq \mu_{2}
\end{aligned}
$$

$H_{0}$ : rata-rata hasil belajar pada materi bangun ruang sisi lengkung dengan menggunakan penerapan alat peraga melalui model pembelajaran Numbered Heads Together tidak lebih baik dari rata-rata hasil belajar pada materi bangun ruang sisi lengkung tanpa menggunakan alat peraga melalui model pembelajaran Numbered Heads Together.

$H_{1}$ : rata-rata hasil belajar pada materi bangun ruang sisi lengkung dengan menggunakan penerapan alat peraga melalui model pembelajaran Numbered Heads Together lebih baik dari rata-rata hasil belajar pada materi bangun ruang sisi lengkung tanpa menggunakan alat peraga melalui model pembelajaran Numbered Heads Together.

Karena $\mathrm{n}$ yang sama $\left(\mathrm{n}_{1}=\mathrm{n}_{2}\right)$ dan varian data homogen, maka pengujian t-test menggunakan rumus polled varian. Peneliti menggunakan aplikasi SPSS 17 untuk mempermudah perhitungan. Perhitungan selanjutnya terdapat pada lampiran 21.

\section{Tabel 6.}


Hasil Uji T-test Postest hasil belajar siswa

Group Statistics

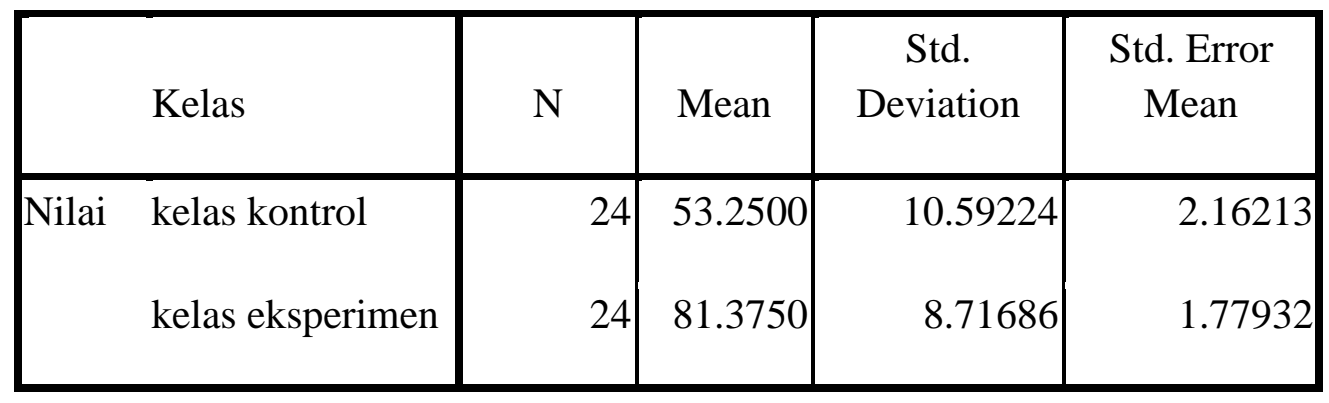

\begin{tabular}{|c|c|c|c|c|}
\hline \multicolumn{5}{|c|}{ Independent Samples Test } \\
\hline & & & \multicolumn{2}{|c|}{ Pretest } \\
\hline & & & $\begin{array}{c}\text { Equal } \\
\text { variances } \\
\text { assumed }\end{array}$ & $\begin{array}{c}\text { Equal } \\
\text { variances } \\
\text { not assumed }\end{array}$ \\
\hline \multirow{2}{*}{$\begin{array}{l}\text { Levene's Test } \\
\text { for Equality } \\
\text { of Variances }\end{array}$} & & $\mathrm{F}$ & 1.901 & \\
\hline & & Sig. & .175 & \\
\hline \multirow{7}{*}{$\begin{array}{l}\text { t-test for } \\
\text { Equality of } \\
\text { Means }\end{array}$} & & $\mathrm{T}$ & 10.044 & 10.044 \\
\hline & & Df & 46 & 44.357 \\
\hline & & Sig. (2-tailed) & 000 & .000 \\
\hline & & Mean Difference & -28.12500 & -28.12500 \\
\hline & & $\begin{array}{l}\text { Std. Error } \\
\text { Difference }\end{array}$ & 2.80014 & 2.80014 \\
\hline & $95 \%$ & Lower & -33.76140 & -33.76140 \\
\hline & $\begin{array}{l}\text { Interval of } \\
\text { the } \\
\text { Difference }\end{array}$ & Upper & -22.48860 & -22.48296 \\
\hline
\end{tabular}

Berdasarkan hasil perhitungan SPSS di atas diperoleh nilai sign(2tailed) sebesar $0,000<0,05$ atau dengan melihat nilai $\mathrm{T}_{\text {hitung }}$ nya yaitu $10,044>\mathrm{t}$ tabel yaitu 2,0129 maka sesuai dengan dasar pengambilan keputusan dari Uji Independent Sample T-test, maka dapat disimpulkan 
bahwa $\mathrm{H}_{0}$ ditolak dan $\mathrm{H}_{1}$ diterima, berarti ada pengaruh yang signifikan antara penerapan alat peraga melalui model pembelajaran Numbered Head Together (NHT) terhadap hasil belajar materi bangun ruang sisi lengkung di kelas IX SMP N 5 Padangsidimpuan.

\section{c. Pembahasan dan Hasil Penelitian}

Penelitian ini dilakukan peneliti untuk mengetahui pengaruh penerapan alat peraga melalui model pembelajaran numbered heads together pada materi bangun ruang sisi lengkung di kelas IX SMP Negeri 5 Padangsidimpuan.

Berdasarkan hasil penelitian menunjukkan bahwa kedua kelas baik kelas eksperimen maupun kelas kontrol dimulai pada saat kondisi yang seimbang dan sama, yang diketahui setelah diadakan uji normalitas dan uji homogenitas pada pretest, ini dapat dilihat dari hasil rata-rata kelas eksperimen $=46,67$ dan rata-rata kelas kontrol $=50,00$. Artinya kedua kelas baik kelas eksperimen maupun kelas kontrol terlihat tidak ada perbedaan yang signifikan antara kemampuan awal siswa.

Setelah diberikan pretest, kelas eksperimen diberikan perlakuan dengan menerapkan alat peraga melalui model pembelajaran numbered heads togeher (NHT) dan kelas kontrol diberikan pembelajaran dengan konvensional.

Pada saat kegiatan pembelajaran belangsung, siswa di kelompok kontrol tidak tertarik dengan materi pelajaran yang diberikan. Mereka jarang merespon dan memberikan reaksi terhadap apa yang disampaikan pada saat proses belajar mengajar. Jika guru bertanya kepada siswa, maka siswa hanya terdiam saja tanpa menjawab. Jika guru meminta siswa untuk maju ke depan kelas untuk menunjukkan unsur-unsur bangun ruang sisi lengkung, hanya sedikit siswa yang maju dengan inisiatifnya sendiri. Guru harus menunjuk siswa untuk maju ke depan. Siswa kelompok kontrol cenderung tidak memberikan perhatian yang besar terhadap pelajaran. Hal tersebut terlihat dari senangnya siswa bermain dengan teman-teman di sekitarnya daripada harus memperhatikan guru yang sedang menjelaskan materi di depan.

Keterlibatan siswa di kelompok kontrol sangat kurang, karena media yang dipakai tidak dapat dimanipulasi. Kegiatan belajar melalui indera lain tidak dapat dicapai melalui media konvensional. Pada saat pembelajaran di kelompok kontrol, siswa cenderung pasif. Mereka hanya mendengarkan guru menjelaskan materi dengan dibantu media konvensional. Berbagai kondisi tersebut mengakibatkan hasil belajar siswa kelompok kontrol tidak optimal.

Berbeda dengan kegiatan pembelajaran di kelompok eksperimen. Saat pembelajaran di kelompok eksperimen, siswa menyukai pelajaran matematika. Hal tersebut dapat peneliti lihat dari semangat siswa dalam mengerjakan tugas. Siswa sangat antusias ketika guru membagikan alat-alat untuk membuat alat peraga bangun ruang sisi lengkung. Siswa sebagian besar mengangkat tangan ketika guru memberi kesempatan untuk maju mengerjakan tugas. Alat peraga bangun ruang sisi lengkung ini dapat lebih 
mudah membantu siswa dalam mengikuti pembelajaran. Dan secara langsung alat peraga ini mampu mengaktifkan kegiatan pembelajaran. Siswa cepat merespon dan memberikan reaksi terhadap apa yang disampaikan oleh guru. Misalkan ketika guru bertanya, siswa secara serentak menjawab dengan keras.

Berdasarkan hasil uji t hasil belajar yang dilakukan oleh peneliti diperoleh bahwa $t_{\text {hitung }}<t_{\text {tabel. }}$ Variabel hasil belajar di uji dengan menggunakan rumus Polled varian karena kedua sampel homogen dan jumlah $\mathrm{n}$ sama, maka di dapat hasilnya $\mathrm{t}$ hitung $<\mathrm{t}_{\text {tabel }}(0,000<0,05)$, artinya $\mathrm{H}_{1}$ diterima.

\section{Penutup}

\section{Kesimpulan}

Berdasarkan hasil penelitian dan analisis data, maka peneliti mengambil kesimpulan bahwa terdapat pengaruh signifikan (meyakinkan) antara penggunaan alat peraga melalui model pembelajaran numbered heads together (NHT) terhadap hasil belajar siswa pada materi bangun ruang sisi lengkung di kelas IX SMP Negeri 5 Padangsidimpuan. Hal ini ditunjukkan dari hasil uji hipotesis yang menunjukkan $t_{\text {hitung }}>\mathrm{t}_{\text {tabel }}(10,044<2,0129)$. Dari perhitungan tersebut jelas terlihat penolakan $\mathrm{H}_{0}$ dan penerimaan $\mathrm{H}_{1}$. Artinya rata-rata hasil belajar aspek kemampuan kognitif siswa pada materibangun ruang sisi lengkung dengan menggunakan alat peraga melalui model pembelajaran numbered heads together (NHT) lebih baik dari pada rata-rata hasil belajar siswa yang menggunakan model pembelajaran konvensional.

\section{Saran}

Berdasarkan kesimpulan penelitian, maka yang menjadi saran peneliti dalam hal ini adalah :

1. Kepada guru SMP N 5 Padangsidimpuan umumnya dan khususnya guru matematika disarankan agar dalam proses pembelajaran menggunakan model dan strategi pembelajaran sesuai dengan materi pelajaran agar proses pembelajaran terlakasana dengan baik.

2. Pembelajaran matematika dengan penggunaan alat peraga melalui model pembelajaran numbered heads together perlu dikembangkan dan digunakan dalam pokok bahasan yang lain sehingga siswa dapat lebih termotivasi dalam proses pembelajaran dan hasil belajarnya akan lebih meningkat.

3. Bagi siswa, diharapkan dapat lebih aktif dan berani dalam mengemukakan pendapat pada pembelajaran matematika.

4. Bagi Kepala Sekolah, agar memperhatikan segala yang berkaitan dengan kualitas sekolah dengan menyediakan sarana prasarana, terutama buku panduan tentang model dan strategi pembelajaran yang dibutuhkan dalam menunjang pembelajaran.

5. Bagi peneliti selanjutnya diharapkan dapat melakukan penelitian yang lebih mendalam dan dengan sumber yang lebih luas, baik pada materi yang lain maupun pada mata pelajaran yang lain. 


\section{DAFTAR PUSTAKA}

Agus Irianto, Statistik Konsep Dasar, Aplikasi dan Pengembangannya, Jakarta: Kencana, 2004

Agus Suprijono, Cooperative Learning Teori \& Aplikasi Paikem, Yogyakarta: Pustaka Pelajar, 2011

Ahmad Nizar, Statistik Untuk Penelitian Pendidikan, Bandung: Cita Pustaka Media, 2014

Ahmad Tafsir, Filsafat Pendidikan Islami, Bandung: Remaja Rosdakarya, 2008

Anang Ikhwanuddin, "Pengaruh Model Pembelajaran Cooperative Tipe Numbered Head Together (NHT) Terhadap Hasil Belajar Matematika Siswa Kelas VIII MTSN Karangrejo" (https://plus.google.com, diakses pada 30 Mei 2016 pukul 11.25)

Anas Sudijono, Pengantar Statistik Pendidikan, Jakarta: Raja Grafindo Persada, 2005

Aunurrahman, Belajar Dan Pembelajaran, Badung: Alfabeta, 2013

Azhar Arsyad, Media Pembelajaran, Jakarta: PT Raja Grafindo Persada, 2007

Bambang Prasetyo dan Lina Miftahul Jannah, Metode Penelitian Kuantitatif, Jakarta: PT Raja Grafindo Persada, 2005

Basyiruddin Usman dan Asnawir, Media Pembelajaran, Jakarta: Ciputat Pers, 2002

Dalyono, Psikologi Pendidikan, Jakarta: Rineka Cipta, 2012

Daryanto dan Mulyo Rahardjo, Model Pembelajaran Inovatif, Yogyakarta: Gava Media, 2012

Ella Yulaelawati, Kurikulum dan Pembelajaran, Jakarta: Pakar Karya, 2007

Erman Suherman, dkk, Strategi Pembelajaran Matematika Kontemporer, Bandung: UPI, 2001

Hasratuddin, Mengapa Harus Belajar Matematika ?, Medan: Perdana, 2015

Heri Rahyubi, Teori-Teori Belajar dan Aplikasi Pembelajaran Motorik (Deskripsi dan Tinjauan Kritis), Bandung: Nusamedia, 2012 
Ibnu Hajar, Dasar-Dasar Metodologi Penelitian Kwantitatif Dalam Pendidikan, Jakarta: PT. Raja Grafindo Persada, 1999

Isjoni, Cooperative Learning, Bandung, Alfabeta, 2013

Istarani, Model Pembelajaran Inovatif, Medan: Persada Medan 2011

Kunandar, Guru Profesional, Jakarta: Rajawali Pers, 2010

M. Chabib Thoha, Teknik Evaluasi Pendidikan, Jakarta: PT. Raja Grafindo Persada, 1996

M. Ngalim Purwanto, Prinsip-Prinsip Evaluasi Pendidikan, Bandung: Remaja Rosdakarya, 2002

Margono, Metodologi Penelitian Pendidikan, Jakarta: Rineka Cipta, 2010

Masda Sitompul, "Pengaruh Penggunaan Alat Peraga Terhadap Hasil Belajar Matematika Siswa Pada Materi Bangun Datar Kelas VII SMP Negeri 1 Dolok Kec. Dolok Kab. Padang Lawas" (IAIN Padangsidimpuan, 2015)

Muhibbin Syah, Psikologi Belajar, Jakarta: Raja Grafindo Persada, 2008

Mulyono Abdurrahman, Anak Berkesulitan Belajar (Teori, Diagnosis, dan Remediasinya), Jakarta: PT. Rineka Cipta, 2012

Ridha Sri Wahyuni, Model Pembelajarn Kooperatif Tipe Numbered Head Together (http:// http://ridha90.blogspot.co.id// diakses pada tanggal 01 Juni 2016 pukul 20.10).

Slameto, Belaar dan Faktor-faktor Yang Mempengaruhi, Jakarta: Rineka Cipta, 2003

Nana Sudjana, Metoda Statistika, Bandung: Tarsito, 2005

Sugiyono, Alat Peraga Dalam Pembelajaran Matematika (http://www.academia.edu/diakses pada Selasa, 31 Mei 2016 pukul 10.04)

Sugiyono, Metode Penelitian Bisnis, Bandung: Alfabeta, 2005 , Metode Penelitian Kuantitatif, Kualitatif dan $R \&$ D, Bandung: Alfabeta Bandung, 201080.

Suharsimi Arikunto, Dasar-Dasar Evaluasi Pendidikan, Jakarta: Bumi Aksara, 2012 
128 Pengaruh Penerapan Alat Peraga.........Intan Parwati Pane, dkk

Prosedur Penelitian Suatu Pendekatan Praktik, Jakarta: Rineka Cipta, 2000

Sukardi, Evaluasi Pendidikan Prinsip dan Operasionalnya, Jakarta: Bumi Aksara, 2008

Tukiran Taniredja dan Hidayati Mustafidah, Penelitian Kuantitatif (Sebuah Pengantar), Bandung: Alfabeta, 2012

Turmudi dan Aljupri, Pembelajaran Matematika, Jakarta: Direktorat Jenderal Pendidikan Islam Departemen Agama Republik Indonesia, 2009

Wina Sanjaya, Perencanaan dan Desain Sistem Pembelajaran, Jakarta: Kencana Prenada Media Group, 2008

Yusiriza, "Alat Peraga Matematika", (http://yusiriza.files.wordpress.com. Diakses pada tanggal 26 Mei 2016 pukul 14.55. Wib)

Zainal Arifin, Penelitian Pendidikan Metode dan Paradigma Baru, Bandung: Remaja Rosdakarya Offset, 2011

Zubaedi, Desain Pendidikan Karakter: Konsepsi dan Aplikasinya dalam Lembaga Pendidikan, Jakarta: Kencana Prenada Media Group, 2013 